\title{
Association between the Use of Blood Components and the Five-Year Mortality after Liver Transplant
}

\author{
Bruno Salomé de Morais, TSA 1, Marcelo Dias Sanches 2, Daniel Dias Ribeiro ${ }^{3}$, Agnaldo Soares Lima 2 , \\ Teresa Cristina de Abreu Ferrari ${ }^{4}$, Malvina Maria de Freitas Duarte ${ }^{5}$, \\ Guilherme Henrique Gomes Moreira Cançado 6
}

Summary: Morais BS, Sanches MD, Ribeiro DD, Lima AS, Ferrari TCA, Duarte MMF, Cançado GHGM - Association between the Use of Blood Components and the Five-Year Mortality after Liver Transplant.

Background and objectives: Liver transplant (LT) surgery is associated with significant bleeding in $20 \%$ of cases, and several authors have demonstrated the risks related to blood components. The objective of the present study was to evaluate the impact of using blood components during hospitalization in five-year survival of patients undergoing LT.

Methods: One hundred and thirteen patients were evaluated retrospectively. Several variables, including the use of blood components intraoperatively and throughout hospitalization, were categorized and evaluated by univariate analysis using Fisher's test. A level of significance of $5 \%$ was adopted. Results with $p<0.2$ underwent multivariate analysis using multinomial logistic regression.

Results: Parenchymal diseases, preoperative renal dysfunction, and longer stay in hospital and ICU are associated with greater five-year mortality after LT $(p<0.05)$. Unlike the intraoperative use of blood components, the accumulated transfusion of packed red blood cell, frozen fresh plasma, and platelets during the entire hospitalization was associated with greater five-year mortality after liver transplantation $(p<0.01)$.

Conclusions: This study emphasizes the relationship between the use of blood components during hospitalization and increased mortality in five years after LT.

Keywords: Blood Component Transfusion; Liver Transplantation; Fatal Outcome.

[Rev Bras Anestesiol 2011;61(3): 286-292] @Elsevier Editora Ltda.]

\section{INTRODUCTION}

Liver transplantation (LT) is the only definitive treatment for end-stage liver disease. Even with the great advance and improvement of surgical results, since it was first described in 1963 by Starzl, LT still has high morbidity because it is a complex surgery performed in patients with multisystem involvement and poor functional reserve.

In recent years, a considerable reduction in the use of blood components has been observed in LT ${ }^{1-5}$. However,

Received from Hospital das Clínicas da Universidade Federal de Minas Gerais (UFMG), Brazil.

1. M.Sc., Ph.D. in Medicine from UFMG; Member of SBA Organ Transplant Commitee, Anesthesiologist of the Grupo de Transplante of Instituto Alfa de Gastroenterologia/UFMG and Hospital Lifecenter

2. M. D. from UFMG; Surgeon of the Grupo de Transplantes of Instituto Alfa de Gastroenterologia (IAG)/UFMG, Professor of Surgery/UFMG

3. M. D. in Medicine from UFMG; Hematologist and Clinical Pathologist

4. M. D. from UFMG; Professor of Internal Medicine of UFMG

5. M.Sc. Student in Medicine at UFMG; Nursing Professor of PUC-MG and Nurse of the

Grupo de Transplantes of Hospital das Clínicas da UFMG

6. Medical Student/UFMG; Scholarship from FAPEMIG

Submitted on July 14, 2010.

Approved on December 7, 2010.

Correspondence to:

Dr. Bruno Salome de Morais

Avenida do Contorno, 4747/19ㅇaㅁ andar

Funcionários

30110060 - Belo Horizonte, MG, Brazil

E-mail: brunomoraisanest@yahoo.com.br the surgery is associated with significant bleeding in $20 \%$ of cases ${ }^{6}$.

Some authors ${ }^{7-10}$ have correlated the intraoperative use of blood components with a reduction in one-year survival after LT. However, there is a lack of studies evaluating the total impact of blood components received during hospitalization and survival after LT.

The main objective of the present study was to evaluate the association of blood transfusion from surgery to hospital discharge with five-year survival of patients undergoing LT.

\section{METHODS}

This is a retrospective study of 113 patients undergoing orthotopic liver transplantation at the Hospital das Clínicas (HC) of Universidade Federal de Minas Gerais (UFMG) between 2001 and 2004. After exclusion of patients younger than 18 years of age $(n=11)$, live donor liver transplantation $(n=3)$, retransplantation $(n=2)$, surgery due to fulminant hepatitis $(n=2)$, and death intraoperatively or within the first 24 hours after surgery $(n=2)$, the data from 93 patients were analyzed. Follow-up was terminated in September 2009. The piggyback surgical technique was used in all patients.

Several variables regarding the receiver were evaluated: age, sex, baseline liver disease (Model of End-stage Liver Disease - MELD), calculated creatinine clearance (Cockcroft-Gault equation), duration of surgery, length of stay in 
the intensive care unit (ICU), and duration of hospitalization. Patients were separated according to the use of blood components and they were also classified according to the sum of blood components transfusion (Table I).

Patients were classified into four groups according to MELD at the time of surgery: $\leq 10,11$ to 18,19 to 24 , and $\geq 25$. This categorization followed the standardization of the Health Ministry for the validity of exams in order to be placed in the waiting list.

Regarding baseline liver disease, the classification was made into categories: parenchymatous, cholestatic, and others.

Preoperative renal dysfunction was characterized according to a creatinine clearance lower than $70 \mathrm{~mL} \cdot \mathrm{min}^{-1}$.

The initial data analysis as well as the results obtained in the literature guided the categorization of continuous variables.

Based on from database, a descriptive analysis was performed on sex, age, primary diagnosis, preoperative renal function, CTP, MELD, duration of surgery, length of stay in $\mathrm{ICU}$, duration of hospitalization, transoperative transfusion of packed red blood cell (PRBC), frozen fresh plasma (FFP), platelets, and cryoprecipitate (CRIO), as well as transfusion of PRBC, FFP, platelets, and CRIO during the entire hospitalization period. Fisher's test was used to determine the association between survival and descriptive variables. A level of significance of $5 \%$ was used. The results of univariate analysis with $p<0.2$ underwent multivariate analysis. Multinomial logistic regression was used in the multivariate analysis. The SPPP, version 10.0, and StatXact, version 4, were the statistical software used.

\section{RESULTS}

Of the 93 patients, 60 (64.5\%) were male. Their age ranged from 18 to 75 years, with a mean of $48.8 \pm 10.97$ years. Regarding the baseline liver disease, $77(82.8 \%)$ were parenchymatous, $10(10.8 \%)$ cholestatic, and $6(6.5 \%)$ were classified as others.

Twelve (12.9\%) patients were classified as CTP A, 65 $(69.9 \%)$ as $B$, and 16 (17.2\%) as C. The MELD ranged from 9 to 36 , with a median of 16 . Preoperative renal dysfunction had an incidence of $27.6 \%$.

Table II shows the use of blood components intraoperatively and during hospitalization.

During surgery, $26.9 \%$ of patients did not receive any blood transfusion, while $10.8 \%$ did not receive blood products during hospitalization.

The duration of the surgery ranged from 4 hours and 20 minutes to 12 hours, with a mean of 7:02h $\pm 1: 32 \mathrm{~h}$. The length of stay in ICU ranged from 3 to 19 days, with a mean of $4.29 \pm 3.37$ days, while the length of postoperative hospitalization ranged from 7 to 90 days, with a mean of $19.32 \pm 13.81$ days.
Table I - Sum of Blood Components Transfusion

\begin{tabular}{llll}
\hline Points & 0 & 1 & 2 \\
PRBC & 0 & 1 to 4 & $\geq 5$ \\
Platelets & 0 & 1 to 8 & $\geq 9$ \\
FFP & 0 & 1 to 8 & $\geq 9$ \\
CRIO & 0 & 1 to 12 & $\geq 13$ \\
\hline
\end{tabular}

PRBC: packed-red blood cells; FFP: fresh frozen plasma; CRIO: cryoprecipitate.

Table II - Distribution of the Perioperative Use of Blood Components in Liver Transplantation

\begin{tabular}{|c|c|c|c|c|c|}
\hline & minimum & maximum & mean & SD & median \\
\hline \multicolumn{6}{|c|}{ Intraoperative (units) } \\
\hline PRBC & 0 & 22 & 3.24 & 4.36 & 2 \\
\hline Platelets & 0 & 23 & 3.61 & 5.52 & 0 \\
\hline FFP & 0 & 15 & 0.92 & 2.49 & 0 \\
\hline Cryoprecipitate & 0 & 18 & 1.60 & 4.50 & 0 \\
\hline \multicolumn{6}{|c|}{ During hospitalization (units) } \\
\hline PRBC & 0 & 43 & 8.87 & 9.51 & 6 \\
\hline Platelets & 0 & 92 & 10.11 & 15.20 & 7 \\
\hline FFP & 0 & 57 & 3.77 & 8.17 & 0 \\
\hline Cryoprecipitate & 0 & 44 & 3.69 & 8.40 & 0 \\
\hline
\end{tabular}

SD: standard deviation.

Twenty-two patients $(23.7 \%)$ died within five years, with survival ranging from 2 to 1,495 days, with a mean of $189.77 \pm 357.06$ days and median of 25 days. The causes of death were cardiovascular in three patients $(3.2 \%)$, surgical in six patients $(6.5 \%)$, infectious in eight patients $(8.6 \%)$, and other in five patients (5.4\%). The 30-day, and 1- and 5-year survival was $86 \%, 81 \%$, and $76 \%$, respectively.

The results of univariate analysis are shown in Table III. All variables with $p<0.2$ underwent multivariate analysis, but none of them was proven to be an independent predictor of survival.

\section{DISCUSSION}

The Model of End-stage Liver Disease, the severity criteria for allocation in the waiting list of LT, was not associated with mortality after transplant at the HC of UFMG in the studied period. Several studies have shown contradictory results regarding the capacity of the MELD to predict mortality after liver transplant ${ }^{11-14}$.

Survival rate after LT in patients with cholestatic liver disease was lower than that of patients with parenchymatous disease $(p=0.048)$, which is similar to the results reported in literature ${ }^{15}$. 
Table III - Association of Different Variables with the 5-Year Survival after Liver Transplantation

\begin{tabular}{ll}
\hline & Fisher's test \\
\hline MELD & 0.887 \\
Agx & 0.613 \\
Diagnosis & 0.142 \\
Preoperative renal function & 0.048 \\
Transoperative PRBC & 0.008 \\
PRBC during hospitalization & 0.367 \\
Transoperative FFP & $0.001^{*}$ \\
FFP during hospitalization & 0.072 \\
Transoperative platelets & $0.003^{*}$ \\
Platelets during hospitalization & 0.678 \\
Transoperative cryoprecipitate & $0.008^{*}$ \\
Cryoprecipitate during hospitalization & 0.506 \\
Accumulated transfusion of blood products & 0.16 \\
transoperatively & \\
during hospitalization & 0.879 \\
Duration of surgery & 0.001 * \\
Length of stay in ICU & 0.446 \\
Duration of hospitalization & 0.029 \\
\hline
\end{tabular}

Although relatively frequent in LT, with an incidence that ranges from $10.0 \%$ to $33.0 \%{ }^{16,17}$, preoperative renal dysfunction is difficult to define. Serum creatinine, the most frequently used test, is not a good method for cirrhotic patients since it overestimates the renal function of these patients ${ }^{16}$. The calculated creatinine clearance (Cockcroft-Gault) estimates the glomerular filtration rate, taking into account the sex, weight, and age of the patient, besides the serum creatinine. In patients with liver disease the normal limit should be over $70 \mathrm{~mL} \cdot \mathrm{min}^{-1}$. Preoperative renal dysfunction is associated with increased need for postoperative hemodialysis, primary liver dysfunction, and increased mortality 16,18, having great influence on quality of life and survival of patients after transplants. Similar to other studies, preoperative renal dysfunction was associated with lower survival after LT $(p=0.008)$.

A large variation in the use of blood products, both intraoperatively and during hospitalization was observed. This variation was probably due to a wide heterogeneity in the severity of patients undergoing LT and to risk factors, such as prior abdominal surgeries, coagulopathies, central venous pressure, preoperative levels of hemoglobin, and greater duration of surgery or hospitalization ${ }^{19}$. The mean rate of transfusion in our institution was similar or lower than that reported by other authors ${ }^{1,20-22}$.

In the last 20 years, an important reduction in transfusion has been observed, from a mean of 43 PRBC and 41 FFP per patient to only 0.3 units of $\mathrm{PRBC}$ per patient without FFP ${ }^{9}$. The greater knowledge of transfusion-related complications, associated with improvements in surgical-anesthetic techniques, has contributed for a more rational use of blood components.
Several studies have shown the association between transfusion of PRBC and reduction of survival after $L T$ 1,2,7,8,24. At the same time, physicians are increasingly aware of the immunomodulatory effects caused by transfusion in almost all patients. These effects may increase the risk of nosocomial infections, acute lung injury, and the development of longterm autoimmune disorders ${ }^{25}$. This has been attributed to depression of the immune system, known as transfusion-related immune modulation (TRIM), and changes in blood products that can occur during storage ${ }^{28}$.

The syndrome known as transfusion-related acute lung injury (TRALI) is a non-cardiogenic acute pulmonary edema that can be seen in up to 6 hours after transfusion of plasmacontaining blood components ${ }^{27}$. Patients undergoing LT are at increased risk of developing TRALI, and it has been suggested that ischemia and reperfusion of the graft would represent predisposing conditions ${ }^{28}$.

Univariate analysis, performed by Fisher's test, found an association between the transfusion of PRBC, FFP, and platelets during hospitalization with the 5-year mortality after LT. The same was observed with the total amount of blood components during hospitalization. Unlike other studies, we did not observe an association between the intraoperative use of blood components and mortality. There is no study in the literature that correlates the use of blood components during hospitalization with the 5-year survival rate after LT. The mean operation time in the present study reflects a small percentage $(1.5 \%)$ of the mean total length of hospitalization of these patients.

During hospitalization, several other variables can influence the results of LT and the need for blood transfusions. During LT, better monitoring of coagulopathies and adoption of judicious transfusion protocols have reduced the use of blood components despite the great surgery-related hemodynamic repercussions. It is possible that the lack of postoperative protocols might have exposed patients to unnecessary blood transfusions, therefore leading to an association with a reduction in the survival of this population.

Although the association between the use of blood components during hospitalization and the lower 5-year survival suggests causality, these observations might be due to the fact that the need for blood transfusion is a marker of greater disease severity. Multivariate analysis was performed with some confounding variables; however, none of them proved to be an independent predictive factor of mortality after LT.

The retrospective nature of this study has limitations. Despite these limitations, however, the outcomes of the study represent an alert for the judicious analysis of the risk-benefit ratio when indicating transfusion of blood products in LT.

Future prospective studies may assess whether the adoption of postoperative conducts in LT to reduce the use of blood components will be associated with increased survival. 


\section{REFERÊNCIAS / REFERENCES}

01. de Boer MT, Christensen MC, Amussen M et al. - The impact of intraoperative transfusion of platelets and red blood cells on survival after liver transplantation. Anesth Analg, 2008;106:32-44.

02. Massicotte $L$, Lenis $S$, Thibeault $L$ et al. - Reduction of blood product transfusions during liver transplantation. Can J Anaesth, 2005;52:545546.

03. Frasco PE, Poterack KA, Hentz JG et al. - A comparison of transfusion requirements between living donation and cadaveric donation liver transplantation relationship to model of end-stage liver disease score and baseline coagulation status. Anesth Analg, 2005;101:3037.

04. Mangus RS, Kinsella SB, Nobari MM et al. - Predictors of blood product use in orthotopic liver transplantation using the piggyback hepatectomy technique. Transplant Proc, 2007;39:3207-3213.

05. Massicotte $L$, Beaulieu $D$, Thibeault $L$ et al. - Coagulation defects do not predict blood product requirements during liver transplantation. Transplantation, 2008; 85:956-962.

06. Massicotte L, Sassine MP, Lenis $S$ et al. - Transfusion predictors in liver transplant. Anesth Analg, 2004;98:1245-1251.

07. Cacciarelli TV, Keeffe EB, Moore DH et al. - Effect of intraoperative blood transfusion on patient outcome in hepatic transplantation. Arch Surg, 1999;134:25-29.

08. Ramos E, Dalmau A, Sabate A et al. - Intraoperative red blood cell transfusion in liver transplantation: influence on patient outcome, prediction of requirements, and measures to reduce them. Liver Transpl, 2003;9:1320-1327.

09. Massicotte L, Sassine MP, Lenis $S$ et al. - Survival rate changes with transfusion of blood products during liver transplantation. Can J Anaesth, 2005;52:148-55.

10. Hendriks HG, Van der Merr J, de Wolf JT et al. - Intraoperative blood transfusion requirement is the main determinant of early surgical reintervention after orthotopic liver transplantation. Transpl Int, 2005; 17:673-679.

11. Hayashi PH, Forman L, Steinberg T et al. - Model for end-stage liver disease score does not predict patient or graft survival in living donor liver transplant recipients. Liver Transpl, 2003;9:737-40.

12. Onaca NN, Levy MF, Sanchez EQ et al. - A correlation between the pretransplantation MELD score and mortality in the first two years after liver transplantation. Liver Transpl, 2003;9:117-123.

13. Desai NM, Mange KC, Crawford MD et al. - Predicting outcome after liver transplantation: utility of the model for end stage liver disease and a newly derived discrimination function. Transplantation, 2004;77:99106.

14. Habib S, Berk B, Chang CH et al. - MELD and prediction of post-liver transplantation survival. Liver Transpl, 2006;12:440-447.

15. Adler M, Gavaler JS, Duquesnoy R et al. - Relationship between the diagnosis, preoperative evaluation and prognosis after orthotopic liver transplantation. Ann Surg, 1988;208:196-202.

16. Nair $S$, Verma $S$, Thuluvath $P$ - Pretransplant renal function predicts survival in patients undergoing orthotopic liver tranplantation. Hepatology, 2002;35:1179- 1185.

17. Afonso RC, Hidalgo R, Zurstrassem MPVC et al. - Impact of renal failure on liver transplantantation survival. Transplant Proc, 2008;40:808810.
18. Biancofiore $G$, Davis $C L$ - Renal dysfunction in the perioperative liver transplant period. Curr Opin Organ Transplant, 2008;13:291-297.

19. Mangus RS, Kinsella SB, Nobari MM et al. - Predictors of blood product use in orthotopic liver transplantation using the piggyback hepatectomy technique. Transplant Proc, 2007;39:3207-3213.

20. Marcel RJ, Stegall WC, Suit CT et al. - Continuous small-dose aprotinin controls fibrinolysis during orthotopic liver transplantation. Anesth Analg, 1996;82:1122-1125.

21. Schoroeder RA, Collins BH, Tuttle-Newhall E et al. - Intraoperative fluid management during orthotopic liver transplantation. J Cardiothorac Vasc Anesth, 2004;18:438-441.

22. Massicotte $L$, Lenis $S$, Thibeault $L$ et al. - Effect of low central venous pressure and phlebotomy on blood product transfusion requirements during liver transplantations. Liver Transpl, 2006;12:117-123.

23. Butler $\mathrm{P}$, Israel $\mathrm{L}$, Nusbacher $\mathrm{J}$ et al. - Blood transfusion in liver transplantation. Transfusion, 1985;25:120-123.

24. Mor E, Jennings L, Gonwa TA et al. - The impact of operative bleeding on outcome in transplantation of the liver. Surg Gynecol Obstet, 1993;176:219-227.

25. Raghavan M, Marik PE - Anemia, allogenic blood transfusion, and immunomodulation in the critically ill. Chest, 2005;127:295-307.

26. Vamvakas EC, Blajchman MA - Transfusion-related immunomodulation (TRIM): an update. Blood Rev, 2007;21:327-348.

27. Kleinman S, Caulfield T, Chan $P$ et al. - Toward an understanding of transfusion- related acute lung injury: statement of a consensus panel. Transfusion, 2004;44:1774-1789.

28. Yost CS, Matthay MA, Gropper MA - Etiology of acute pulmonary edema during liver transplantation: a series of cases with analysis of the edema fluid. Chest, 2001;119:219-223.

Resumen: Morais BS, Sanches MD, Ribeiro DD, Lima AS, Ferrari TCA, Duarte MMF, Cançado GHGM - Asociación entre el Uso de Hemocomponentes y la Mortalidad en Cinco Años Después de Transplante Hepático.

Justificativa y objetivos: La cirugía de transplante hepático (TH), continúa asociada al sangramiento importante en un $20 \%$ de los casos, y diversos autores ya han demostrado los riesgos relacionados con el uso de hemoderivados. El objetivo de este estudio fue evaluar el impacto del uso de hemoderivados durante toda la hospitalización en la sobrevida en cinco años de pacientes sometidos a TH.

Métodos: Un total de 113 pacientes sometidos a TH fueron evaluados retrospectivamente. Diversas variables, incluyendo el uso de hemoderivados en el intraoperatorio y durante toda la hospitalización, fueron categorizadas y evaluadas por medio de análisis univariado, por el test de Fisher. El nivel de significancia adoptado fue de un $5 \%$. Los resultados con $p<0,2$ fueron sometidos a un análisis multivariado por el modelo de regresión logística multinominal.

Resultados: Enfermedades parenquimatosas, disfunción renal preoperatoria y un mayor tiempo de internación en $\mathrm{UCl}$ y hospitalario, se asociaron a una mayor mortalidad en cinco años después del TH $(p<0,05)$. Al contrario del uso de hemoderivados en el intraoperatorio, la transfusión acumulada de concentrado de hematíes, plasma fresco congelado y concentrado de plaquetas durante todo el ingreso se asoció a una mayor mortalidad en cinco años posteriores al transplante de hígado $(p<0,01)$.

Conclusiones: El estudio es un alerta sobre la relación existente entre el uso de hemoderivados durante el ingreso y el aumento de la mortalidad en cinco años posteriores al TH.

Descriptores: CIRUGÍA, Transplante: hígado; COMPLICACIONES: mortalidad; SANGRE: transfusión. 